DOI: http://dx.doi.org/10.33846/hn40401

http://heanoti.com/index.php/hn

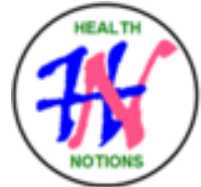

RESEARCH ARTICLE

URL of this article: http://heanoti.com/index.php/hn/article/view/hn40401

\title{
Management of Recurrent Aphthous Stomatitis in a Patient with High Recurrence Frequency
}

\author{
Sri Hernawati ${ }^{1(\mathrm{CA})}$ \\ ${ }^{1(\mathrm{CA})}$ Dentistry Faculty, Universitas Jember / Oral Medicine Department, Dental Hospital of Universitas Jember, \\ Indonesia; srihernawati.drg5@yahoo.com (Corresponding Author)
}

\begin{abstract}
RAS (Recurrent Aphthous Stomatitis) is an inflammation of soft tissues of the oral cavity characterized by recurrent and painful ulcers. These lesions can be marked early on with a burning sensation, and when the wound has formed, the pain is getting worse. Occasional symptoms of precursors, paresthesia and hyperesthesia, are sometimes reported. Pain and discomfort arise along movement around the ulcer e.g. eating, talking and swallowing. Characteristics of RAS are usually single or multiple ulcers occurring recursively on the oral mucosa, round or oval in shape, clearly demarcated, with a grayish-yellow necrotic center and reddish edges. Lesions occur at young ages i.e. children and puberty, and may occur in adults as well. Ulcers usually last in 1 week or month. This disorder is classified into three categories according to size i.e. recurrent aphthous stomatitis minor, major and herpetiformis. The aim of this report is to show the management of cases of Recurrent Aphthous Stomatitis Minor on the left side of tongue, left buccal mucosa, and lower labial mucosa in female patient aged 19 years. A 19-year-old female patient came to the Dental Hospital of Jember University with complaints of thrush on the left side of her tongue, left buccal mucosa and lower labial mucosa, pain, and feeling disturbed due to the pain when eating, talking, and laughing. In this case, the diagnosis showed Recurrent Aphthous Minor Stomatitis on the left side of the tongue, left buccal mucosa, and lower labial mucosa. The therapy was using nonsteroidal anti-inflammatory mouthwash containing aloe Vera and hyaluronic acid as well as giving multivitamin of becomzet (vitamin B complex, A, C, E, and Zinc).
\end{abstract}

Keywords: recurrent aphthous stomatitis; high recurrence

\section{INTRODUCTION}

Recurrent Aphthous Stomatitis (RAS) is an inflammation of the soft tissues of the mouth characterized by lesions in the form of recurrent pain ${ }^{(1)}$. The initial symptoms of RAS can be felt by patients as pain and discomfort when there is movement around the ulcer, e.g. eating, talking and swallowing. Clinical appearance of RAS is characterized by the presence of a single or multiple ulcers that recur in the oral mucosa, round or oval, clear boundary, with a yellow-gray necrotic center and reddish edges and often appear on non-keratinous mucosal areas e.g. the buccal mucosa ${ }^{(2),(3)}$. The emergence of RAS for the first time can be at young ages i.e. children and puberty with repeated risks followed and a greater severity with age ${ }^{(4)}$.

The diagnosis of RAS is based on the history and clinical description of the ulcer. The things that can be of particular concern to the examination including the involvement of family history, frequency of ulcers, duration of ulcers, number of ulcers, location of ulcers (non-keratinization or keratinization), size and shape of ulcers, medical conditions, genital ulcers, skin problems, digestive disorders, medicine history, ulcer edges, ulcer base, and surrounding tissue ${ }^{(5)}$. This is due to the large number of lesions in the oral cavity that clinically resemble RAS, including traumatic ulcers, behcet's syndrome, herpes simplex, and squamous cell carcinoma ${ }^{(1)}$.

Ulcers on RAS are self-limited, can last for 1-2 weeks or months and can be repeated within 3-6 months (6), (4). RAS can be classified into three categories according to size, i.e. recurrent aphthous stomatitis minor, major and herpetiformis ${ }^{(3)}$. Clinical appearance of minor type RAS is a small size with a diameter of less than 1 
$\mathrm{cm}$ or usually around 3-5 mm, the number of ulcers can be single or multiple, ulcers sometimes appear clustered usually the number is less than five, and can heal spontaneously without scar formation within 14 days ${ }^{(1)}$.

The major type of RAS is a formation of severe aphthous stomatitis, with a deeper and larger clinical appearance of ulcer (above $1 \mathrm{~cm}$ ) with a necrotic and concave middle part, which can appear with longer duration, recurrence more frequently and be accompanied by severe pain, and usually found more than one. Depending on its size, the influence of traumatic and secondary infections, ulcers can last 5-10 weeks and heal forming scar tissue ${ }^{(1),(7)}$.

Herpetiformis type of RAS manifests as small ulcers with needle-sized lateral, usually lasting 1-2 weeks, and can heal without leaving scar tissue ${ }^{(7)}$.

The etiology of RAS is not yet certainly known, but a number of predisposing factors are considered related to RAS. Some of these factors include trauma, endocrinopathy, menstruation, nutritional deficiencies, immune dysfunction (stress) or exposure to antigens (food allergies) ${ }^{(1)}$.

The initial appearance of RAS begins with prodromal symptoms which are described as pain, burning or pricking for 24-48 hours before an ulcer ${ }^{(8)}$. The clinical characteristics of RAS are divided into 4 stages, i.e. premonitory, pre-ulcerative, ulcerative and healing. Premonitory stage occurs in the first 24 hours of RAS lesion development. In prodromal symptoms, the patient will feel a burning mouth sensation where the lesion will appear. The pre-ulceration stage occurs in the first 18-72 hours of development of RAS lesions. At this stage, the macula and papules develop with an erythematous edge. The intensity of pain increases during the preulceration stage. The ulcerative phase continues for several days to 2 weeks. At this stage the papules will ulcerate, and the ulcer will be covered by a fibromembranous layer followed by reduced pain intensity. The healing stage occurs on days 4 to 35 . The ulcer will be covered by epithelium. Wound healing occurs and always does not leave scar tissue where RAS lesions have appeared. Therefore, all RAS lesions heal and new lesions can develop ${ }^{(9)}$.

Treatment for RAS is aimed at reducing pain or discomfort and shortening the duration of ulceration by suppressing the local immune response, and preventing secondary infections. Although there is no definitive treatment for RAS, the use of anti-inflammatory is the main treatment method ${ }^{(10)}$.

\section{METHODS}

This study was a case report on a patien with recurrent apthous stomatitis in Dental Hospital of Universitas Jember. This study was conducted on 2020 at The Dental Hospital of Universitas Jember, Indonesia.

\section{RESULTS}

Visit I (March 2, 2020)

A 19-year-old female patient came to the Dental Hospital of Jember University with complaints of thrush on the left side of her tongue, left buccal mucosa, and lower labial mucosa, felt painful, and was uncomfortable when eating and laughing. The patient explained that the main complaint had appeared 5 days before the patient came to the Dental Hospital. She told to have often experienced thrush 1 or 2 times a month in different places. She treated the thrush using topical medication and vitamins consumption, and it usually recovered within 1-2 weeks.

Calculation of Body Mass Index (BMI) results obtained 20.36 (normal). The patient explained that her parents also had a history of recurrent thrush. Clinical examination on the extra oral found multiple vertical fissures with a depth of 0.5-1 $\mathrm{mm}$ accompanied by redness, desquamation, and pain (Figure 1). Intra oral examination found two ulcers on the left side of the tongue with a diameter of $\pm 6 \mathrm{~mm}$ and $\pm 8 \mathrm{~mm}$ respectively, oval shaped, white yellowish ulcer base and surrounded by erythema, clearly demarcated and painful (Figure 2). A single ulcer was found in the left buccal mucosa and lower labial mucosa with a diameter of $\pm 2 \mathrm{~mm}$ and \pm 5 $\mathrm{mm}$, round shape, ulcer base with a yellowish white color surrounded by erythema, clearly demarcated, and painful (Figure 2). 


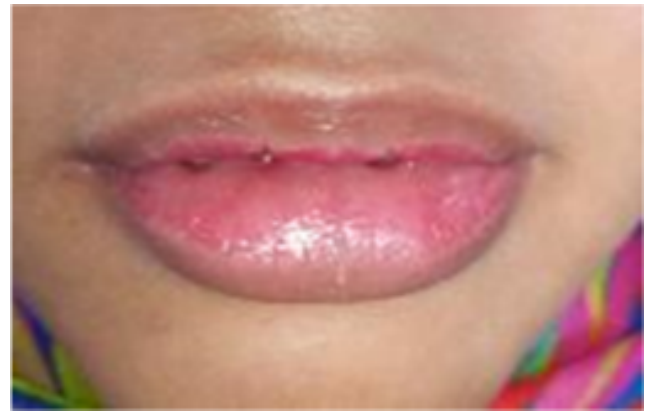

Figure 1. Cheilitis in the upper and lower labials
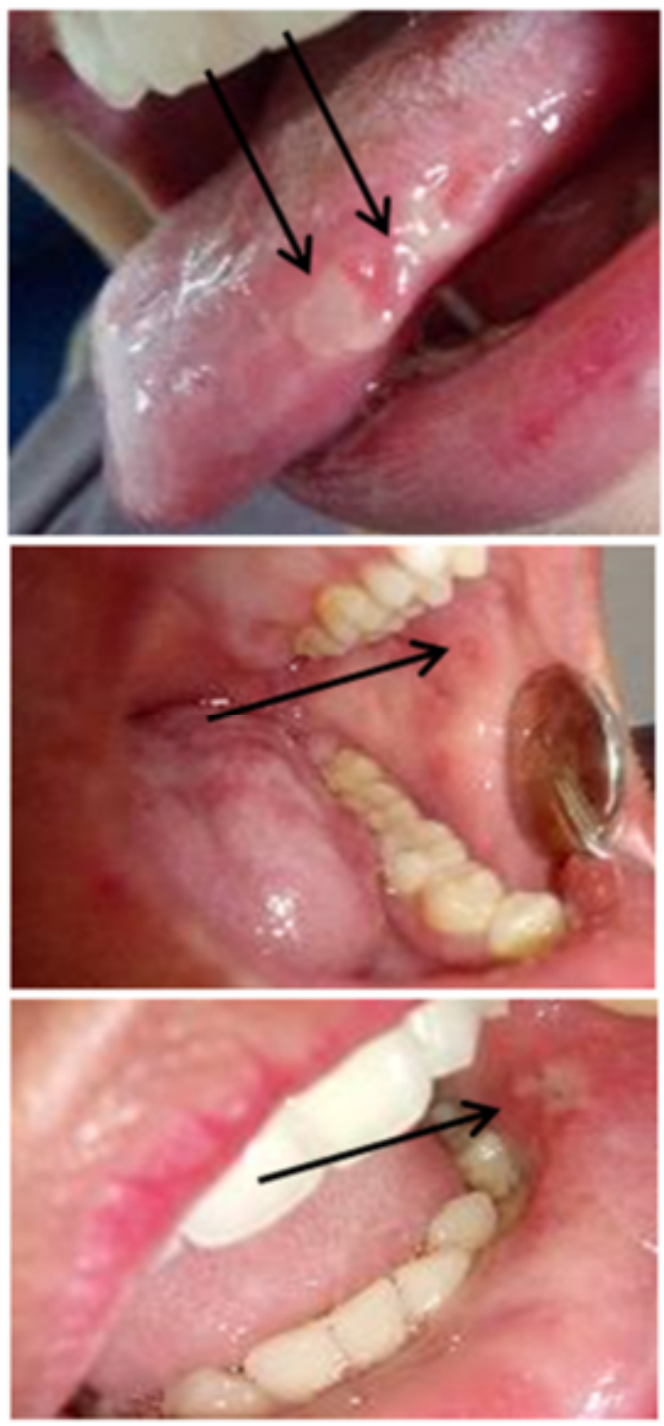

Figure 2. Recurrent aphthous minor stomatitis of the left side of the tongue, left buccal mucosa, and lower labial mucosa.

The Patient's Condition on Her First Visit 
Based on subjective and objective examinations performed, the patient was diagnosed with Recurrent Aphthous Minor Stomatitis on the left side of the tongue, left buccal mucosa, and lower labial mucosa, and cheilitis on the upper and lower lips.

\section{$\underline{\text { Case Management }}$}

Management of patients at the first visit is:

$>$ Thrush on the left side of the tongue, left buccal mucosa, and lower labial mucosa.

a. Asepsis: the patient was instructed to gargle, and the tongue, left buccal mucosa, and labial mucosa were subsequently dried with a sterile cotton roll.

b. Sprue smeared with anti-inflammatory Aloclair oral solution containing aloe vera and hyaluronic acid using sterile cotton pellets.

c. The patient was instructed not to eat, to drink, to gargle and to lick her mouth for 20-30 minutes after anti-inflammatory application.

$>$ Cheilitis on the upper and lower lips.

a. Asepsis: the patient was instructed to gargle, and lips were subsequently dried with a sterile cotton roll.

b. The lips were smeared with topical anti-inflammatory hydrocortisone using a sterile cotton pellet, and afterwards flattened.

c. The patient was instructed not to eat, to drink, to bite and to lick her lips for 20-30 minutes after antiinflammatory application.

Therapy for home application was the provision of anti-inflammatory mouthwash containing aloe vera and hyaluronic acid to reduce inflammation and pain of the thrush. The patient was provided ointment OM to relieve inflammation of her lips. The patient was also provided a multivitamin of becomzet containing vitamin B complex, folic acid, vitamin $\mathrm{C}$, vitamin $\mathrm{E}$, and zinc to improve the physical condition of the patient.

The receipt prescribed from the above explanation is as follows:

R/Aloclair fls No. I

$\S 3 \mathrm{dd} 0,5 \mathrm{ml}$ garg

R/OM ointment No. I

Hydrocortisone $\quad 1 \% \quad 1 \mathrm{~g}$

Vitamin E 200 IU 1/2 caps

Lanolin

Vaselin ad $\quad 5 \mathrm{~g}$

m.f.ung

$2,5 \mathrm{~g}$

$\S$ lit or 3 dd 1

R/ Becomzet tabs No. X

$\S 1$ dd I p.c

Instructions to the patient included to have nutritious and regular meals, to maintain oral hygiene, to have adequate rest, to use and to take the medicine as prescribed, and to go for control (checkup) 1 week later.

\section{Visit II, Control I (March 10, 2020)}

On March 10, 2020, the patient returned to Dental Hospital for control. The patient said that the thrush on the left mucosa and lower labial mucosa had become smaller and painless, while thrush on the left buccal mucosa had healed and had no scar (Figure 3).

On extraoral examination, no abnormalities were found. Intraoral examination revealed ulcers on the dorsum of the tongue and left buccal mucosa with diameters of $\pm 8 \mathrm{~mm}$ and $\pm 3 \mathrm{~mm}$ respectively, round, with a yellowish-white ulcer base surrounded by erythema, clearly demarcated, and painful (Figure 4). 


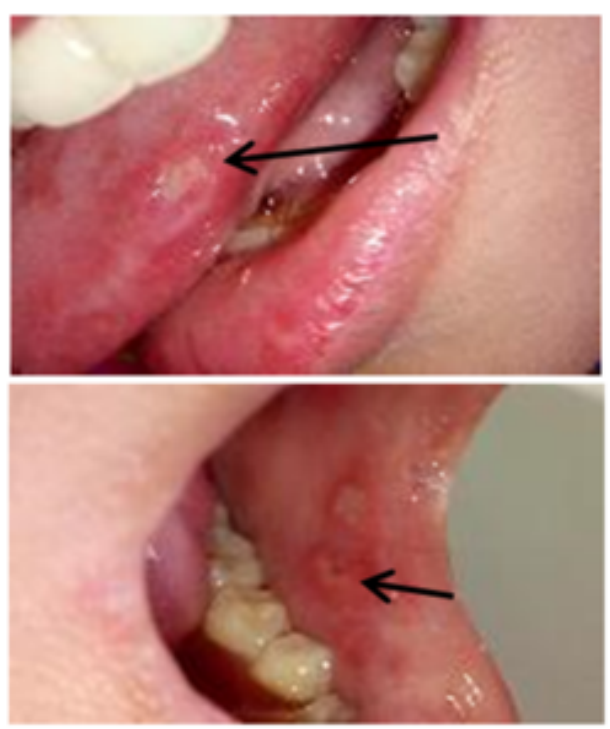

Figure 3. During the second visit, the left side of the tongue and the ulcer were controlled, the left buccal mucosa and the lower labial mucosa were small and painless
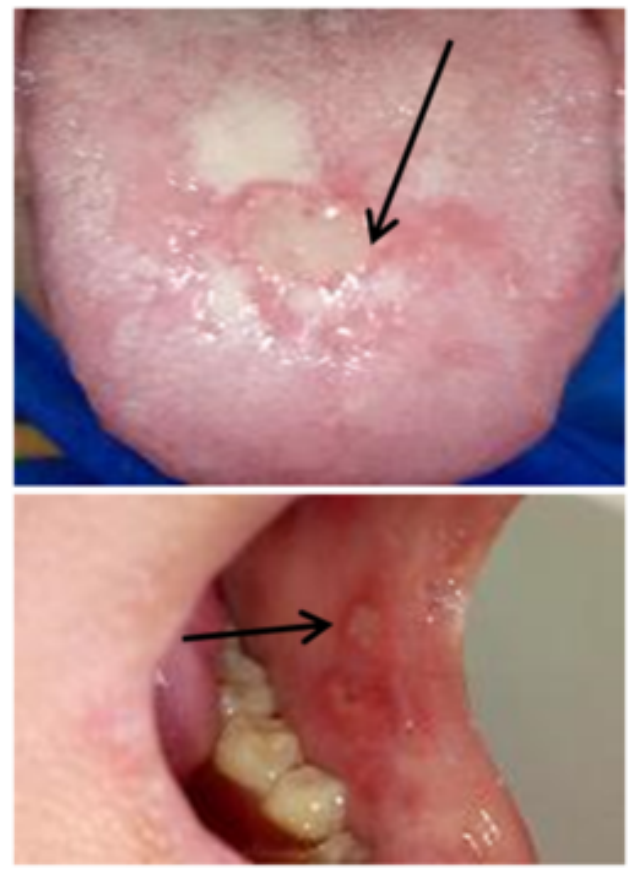

Figure 4. During the second visit a control was performed and a minor recurrent aphthous stomatitis was found in the dorsum of the tongue and left buccal mucosa.

\section{The Patient's Condition on Her Second Visit}

Based on subjective and objective examinations performed at the second visit, the patient was diagnosed with Recurrent Aphthous Stomatitis Minor on the dorsum of the tongue and left buccal mucosa.

Management at the second visit, the patient explained told that mouthwash had run out, thus prescription of nonsteroidal topical anti-inflammatory drugs containing aloe vera and hyaluronic acid was provided. The receipt from the above explanation is as follows: 
R/ Aloclair oral suspension No. I

$\S$ lit.or 3 dd I

The patient was also instructed to continue the application of topical anti-inflammatory on the upper and lower lips according to the instructions at the first visit. The patient was also instructed to maintain oral hygiene, regular diet and adequate rest.

\section{DISCUSSION}

Based on the description of the case, the patient can be diagnosed due to two ulcers on the left side of her tongue with a single ulcer found with a diameter of $\pm 6 \mathrm{~mm}$ and $\pm 8 \mathrm{~mm}$ respectively, oval-shaped, yellowishwhite colored base of surrounded by erythema, clearly demarcated and felt painful. A single ulcer was also found in the left buccal mucosa and lower labial mucosa with a diameter of $\pm 2 \mathrm{~mm}$ and $\pm 5 \mathrm{~mm}$, round, the base of the ulcer was white and surrounded by erythema, clearly demarcated, and felt painful. At the second visit an ulcer was found in the dorsum of the tongue with a diameter of $\pm 8 \mathrm{~mm}$, round shape, ulcer base with a yellowish-white color with erythema edge, clearly demarcated, and felt painful.

The 19-year-old patient was a student of $2^{\text {nd }}$ semester who had been in a busy period in college because of many additional assignments and activities. The patient's age which was young adults had many predisposing factors to trigger RAS, including hormonal changes that accompany growth. The main cause of RAS is unknown, but is thought to be related to various predisposing factors e.g. food allergies in patients, stress, and immunological factors.

Calculation of Body Mass Index (BMI) results obtained 20.36 (normal). The patient had no allergies and bad habits. The patient previously complained of thrush appearing with an unknown cause. However, based on the location of the ulcer, biting area, the trauma could be suspected as the initial cause of RAS. In addition, it was suspected to involve stress factors because the patient was in a busy period of study with various tasks and activities. Stress triggers the hypothalamus pituitary adrenal cortex and subsequently releases vasopressin and CRH (Corticotropin Releasing Hormones) which will increase the hormone cortisol. This cortisol hormone will inhibit the proliferation of T-mast cells (defense against pathogens) and prevent IL-6 and IL-2R signals (mediators of the immune response that decreases the patient's immune system). Once the immune system decreases, even minimal trauma can turn into pathological symptoms [11].

The treatment conducted was by administering nonsteroidal anti-inflammatory and Becomzet multivitamin. The treatment was intended to reduce inflammation and pain when friction occurred, to eliminate local factors that caused pain, to improve body condition, and to reduce pain thus the patient might eat well. The anti-inflammatory administered was Aloclair oral solution containing aloe vera and hyaluronic acid as a covering agent which is a topical anti-inflammatory that can reduce inflammation, pain, and accelerate reepitalization. Aloe vera is thought to have many anti-inflammatory properties, e.g. auxin and gibberellin which have anti-inflammatory and antiseptic properties ${ }^{[12]}$. The multivitamin provided for the patient was a multivitamin becomzet containing vitamin E 30UI which functions as antioxidant, Vitamin C $750 \mathrm{mg}$ for tissue regeneration, carbohydrate metabolism, protein synthesis, lipids, collagen, and folate ac. $400 \mathrm{mg}$ to maintain cell shape, Vitamin B complex functions to produce energy for cells, nervous system, digestion and maintain cholesterol levels, Zinc $22.5 \mathrm{mg}$ as a protein cofactor and constituent of DNA and RNA chains. Instructions to the patient include consumption nutritious foods regularly, always maintaining oral hygiene, drinking lots of water, and having enough rest.

\section{CONCLUSION}

Based on the explanation above, it can be concluded that the patient has Recurrent Aphthous Stomatitis Minor. The condition is unknown, but it is thought to be related to various predisposing factors e.g. trauma, food allergies, menstrual cycle, stress, family history of RAS, and immunological factors. The therapy provided is a topical anti-inflammatory using oral solution to reduce inflammation and pain, a multivitamin of becomzet to increase endurance. The therapy is expected to reduce ulcer swelling due to inflammation and pain suffered by the patient. In addition, the patient is also instructed to maintain oral hygiene, to eat nutritious foods, and to get enough rest.

\section{REFERENCES}

1. Langlais RP, Miller CS. Atlas of Colored Oral Lesions that are Often Found (Atlas Berwarna Lesi Mulut yang Sering Ditemukan). Jakarta: EGC; 2013. 
2. Sulistiyani A, Hernawati S, Mashartini A. Prevalence and distribution of recurrent aphthous stomatitis patients (RAS) in oral disease clinics, RSGM FKG, Universitas Jember in 2014 (Prevalensi dan distribusi penderita stomatitis aftosa rekuren (SAR) di klinik penyakit mulut RSGM FKG Universitas Jember pada tahun 2014). e-Jurnal Pustaka Kesehatan. 2017;5(1).

3. Gavic, Lidia, Livia C, Dolores BL, Vladimir G, Josipa SGP. The Role of anxiaty, depression, and psychological stress on the clinical status of recurrent apthous stomatitis and oral lichen planus. Journal of Oral Pathology and Medicine. 2014;43:410-417.

4. Cui, RZ, AJ Bruce, RS Rogers III. Recurrent Apthous Stomatitis. Clinics in Desmatology. 2016;34:475481.

5. Domino FJ, Baldor RA, Golding J, Grimes JA. The 5-Minute Clinical Consult Premium 2015. $23^{\text {rd }}$ Edition. Philadelphia: Wolters Kluwer Health; 2014.

6. Thantawi A, Khairiati, Nova MM, Marlisa S, Bakar A. Stomatitis apthosa rekusen (SAR) minor multiple pre menstruasi. Odonto Dental Journal. 2014;1(2).

7. Mitchell L, Mitchell DA, McCaul L. Clinical Dentistry (Kedokteran Gigi Klinik). Jakarta: EGC; 2012.

8. Akintoye SO, Greenberg MS. Recurrent Apthous Stomatitis. USA: Departement of Oral Medicine University of Pensylvania; 2014.

9. Roger RS. Recurretn apththuos stomatitis: clinical charactericstic and associated systemic disorder. Seminars in Cutaneus Medicine and Surgery: 1997;16(4);278-283.

10. Nurdiana, Jusri M. Management of major recurrent aphthous stomatitis with secondary infections (Penatalaksanaan stomatitis aftosa rekuren mayor dengan infeksi sekunder). Dentofasial. 2011;1(1):42-46.

11. Field A, Kongman L, Tyldseley W. Tyldesley's Oral Medicine. $5^{\text {th }}$ Ed. New York: Oxford University Press; 2004.

12. Tjahajani A, Widurini. Aloe vera Leag Anti Inflammation's Activity Speeds Up the Healing Proccess of Oral Mucosa Ulceration. Journal of Dentistry Indonesia. 2011;18(1):17-20. 